\title{
Trends in Teenage Sexual Behavior and Births in Europe
}

OSMO KONTULA, Ph.D., Senior Researcher

The Population Research Institute, The Family Federation of Finland

\begin{abstract}
Sexual and reproductive behavior, and outcomes of that behavior, are treated in this article in the framework of sexual and reproductive health. The focus is on teenagers. European trends in sexual behavior and in fertility/births from the 1980s to the late 1990 s are presented.
\end{abstract}

The transition in sexual initiation started first in the Nordic countries, then in many Western European and Central European countries and finally, one generation later, in Southern and Eastern Europe. The age of women at first sexual intercourse decreased several years almost everywhere in Europe. Due to improvements in sex education and in the use of contraceptives, teenage birth rates have been declining, at the same time, around Europe.

There is a serious need for sexual health prevention campaigns and related services in Europe. Work for improvement of sexual and reproductive health and rights can be successful only in a society where there is openness and social tolerance on sexual issues.

Keywords: Sexual behavior, sexual initiation, births, teenagers, Europe, sexual and reproductive health, sexual policy

Sexual and reproductive behavior, and outcomes of that behavior, will be treated in this article in the framework of sexual and reproductive health. At the 1994 International Conference on Population and Development (ICPD) and at the $4^{\text {th }}$ World Conference on Women in Beijing in 1995 the focus was shifted from population control to sexual and reproductive health. The program of Action of the Cairo conference states that reproductive health "implies that people are able to have a satisfying and safe sex life and that they have the capacity to reproduce and freedom to decide if, when and how to do so" (United Nations 1996,1). The document goes on to say that the purpose of sexual health "is the enhancement of life and personal relations, and not merely counseling and care related to reproduction and sexually transmitted diseases". In the new approach, agreed upon by 184 governments, sexual health is considering a vital part of a person's physical and psychological well-being. 
Sexual health is an essential component of general health and includes the avoidance of unintended pregnancies and sexually transmitted infections. The notion of reproductive health encompasses the rights of men and women to make informed choices concerning the number, timing and spacing of their children and to fulfil their reproductive aspirations, ensuring that women's sexuality and childbearing poses no risk to their health and well-being. Reproductive health is the prerequisite and the result of sexual and reproductive behavior. (World Population..., 2002.)

In this article trends in Europe from the 1980s to the late 1990s in sexual behavior and in fertility/births will be presented. The focus is on teenagers. A descriptive analysis will provide an overview of current patterns and trends in adolescent sexual and reproductive health behavior for the European countries where this information is available.

\section{Available data sets}

\section{1) Sex surveys in the Baltic Sea Area}

An exercise of the differences in sexual initiation between Western (Nordic) and Eastern (two geographical areas of the former Soviet Union) European countries has been conducted in the study "FINSEX study and the related sex surveys in the Baltic Sea Area" authored by Osmo Kontula and Elina Haavio-Mannila (Kontula \& Haavio-Mannila, 1995; Haavio-Mannila \& Kontula, 2001; Haavio-Mannila \& Kontula, 2003). The study covers six national sex surveys and one local sex survey (St. Petersburg) in the Baltic Sea Area:

Finland $1971 \quad(\mathrm{~N}=2,188), 1992(\mathrm{~N}=2,250)$, and $1999(\mathrm{~N}=1,496)$;

Sweden $1996 \quad(\mathrm{~N}=2,810)$,

St. Petersburg $1996(\mathrm{~N}=2,085)$, and

Estonia $2000 \quad(\mathrm{~N}=1,031)$.

The age group varies from $18-54$ years to $18-81$ years.

The Swedish survey was originally conducted by Bo Lewin et al. (1998).

\section{2) National Encounter Module surveys}

The most important entities of the data sets available for the study were the national surveys "The New Encounter Module (NEM) for following up HIV/AIDS prevention in general population surveys". The project was funded by the EU 'Europe against AIDS' Program. These surveys provide the latest national trend information on sexual behavior in these countries.

The aim of the project was to follow up (1) the way HIV/AIDS prevention is or is not taken into account in new relationships and (2) key indicators of sexual behavior 
and HIV/AIDS prevention. The approach was not centered on the individual exclusively but also on the characteristics of the relationship. Of special interest were the last new encounters (last new partner) with a sexual partner. The surveys were based on a common questionnaire: 'Sexual Behavior and Risks of HIV Infection in Europe'. The target population has been the general population in each country. It was strongly recommended that probability samples be built.

The following national NEM surveys were conducted in Western Europe in the late 1990s (in Spain in the early 2000s) in the age group of 18-49 years (country, year of data collection, number of respondents, response rate):

$\begin{array}{lccc}\text { Country } & \text { Year } & \mathrm{N} & \text { Response rate } \\ \text { Norway } & 1997 & (\mathrm{~N}=3,723) & 37.2 \% \\ \text { England } & 1998 & (\mathrm{~N}=2,935) & 77.9 \% \\ \text { Germany } & 1998 & (\mathrm{~N}=2,583) & 68.7 \% \\ \text { France } & 1998 & (\mathrm{~N}=1,614) & 75.9 \% \\ \text { Portugal } & 1999 & (\mathrm{~N}=1,000) & 86.0 \% \\ \text { Switzerland } & 1997 & (\mathrm{~N}=2,777) & 68.9 \% \\ \text { Spain } & 2001 & (\mathrm{~N}=2,935) & 69.9 \% \\ \text { Italy } & 1998 & (\mathrm{~N}=2,603) & 80.9 \% \\ \text { Greece } & 1998 & (\mathrm{~N}=2,000) & 84.1 \%\end{array}$

The lower response rate in Norway is due to a mailed data collection technique. This technique was not applied in the other countries. They conducted either face-to-face surveys or telephone surveys. A copy of each survey data set was centralized in Brussels ${ }^{1}$.

\section{3) CDC surveys}

The Centers for Disease Control and Prevention in Atlanta have coordinated CDCsurveys in Eastern Europe in collaboration with several national organizations. These surveys are available from Ukraine (1999), Romania (1999), Moldova (1997), Georgia (2000), and the Czech Republic (1993). City-level CDC-surveys are also available for the cities of Ekaterinburg and Perm in Ivanovo Oblast, Russia (1999 Russia Women's Reproductive Health Survey).

\section{4) Information on live births}

The trend information on live births among teenage women (age group <20) in Europe in this article is mostly based on 'Recent demographic developments in Europe 2001', Council of Europe.

\footnotetext{
1 More information on data sets is available at http://www.fusl.ac.be/Files/General/ces/ rechsida.AC2.html.
} 


\section{Sexual behavior among teenagers and young adults}

Sexual initiation includes a variant of individual desires, feelings and behavior patterns. Standards and definitions vary from country to country. However, the first sexual intercourse has been generally adopted as a turning point in the intimacy experiences and final evidence of the completion of sexual initiation. The age at first intercourse is an important indicator of sexual behavior, both individually and culturally, and of its individual variations among teenagers and young adults.

Traditionally, female sexual initiation was closely linked with marriage ${ }^{2}$. Women were supposed to be initiated into sex by their husbands, especially in Southern European countries. The spread of reliable birth control methods, the rise in women's level of education, women's rapidly growing participation in the labor force and more tolerant values in sexual issues have caused a notable increase in female sexual autonomy. As a consequence, the age at first intercourse has decreased in Europe. At the same time, the period from the first intercourse to cohabitation or marriage has increased. Modern teenagers and young adults have less committed sexual experiences than the generation of their parents. As a consequence, young people more often also face a risk of pregnancy in their sexual encounters.

In the Baltic Sea Area women's age at first intercourse had decreased around four years from older generations (born 1917-1931) to younger generations (born 19671980) (Figure 1). Almost similar decreases were found in Finland, Sweden, Estonia and Russia (St. Petersburg), but the timing was 20-30 years later in the former parts of the Soviet Union. Among males the similar decrease was only two years. The trend found in Estonia and St. Petersburg resembles the trend found in Southern Europe. On the average, the declining trend has taken place there one generation later than in the other Western countries.

The sexual behavior of young people varied by area, gender and generation. Age at first intercourse was much higher in the East than in the West. Men had started to have coitus at an earlier age than women in the Finnish survey conducted in the early 1970s and in the St. Petersburg survey conducted in the 1990s (Figure 2). In the other populations the gender differences were small. Young people had begun having intercourse earlier than older people. Gender gaps in the age at first intercourse were wider in the older than in the younger age groups. An interesting finding was that in Finland in 1999 and in Sweden in 1996, young women had started sexual intercourse at an earlier age than young men.

2 This is still true in most countries in the developing world (Kontula, 2000). 
Figure 1. Median age at first intercourse. Women by generation.

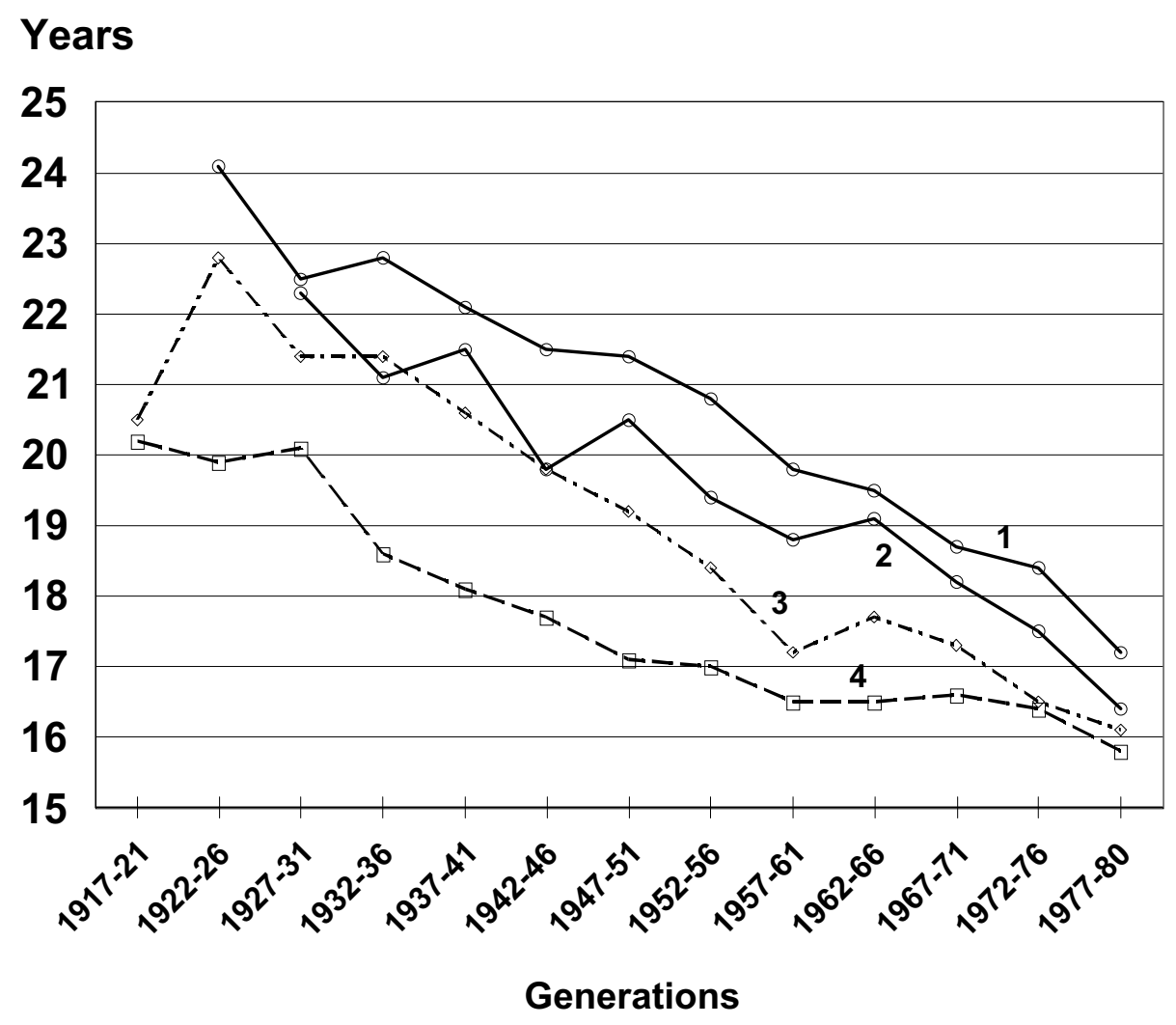

1. St. Petersburg 1996

2. Estonia 2000

3. Finland 1999 - - - - .

4. Sweden 1996 $-\rightarrow-$

Figure 2. Median age at first intercourse. Men by generation.

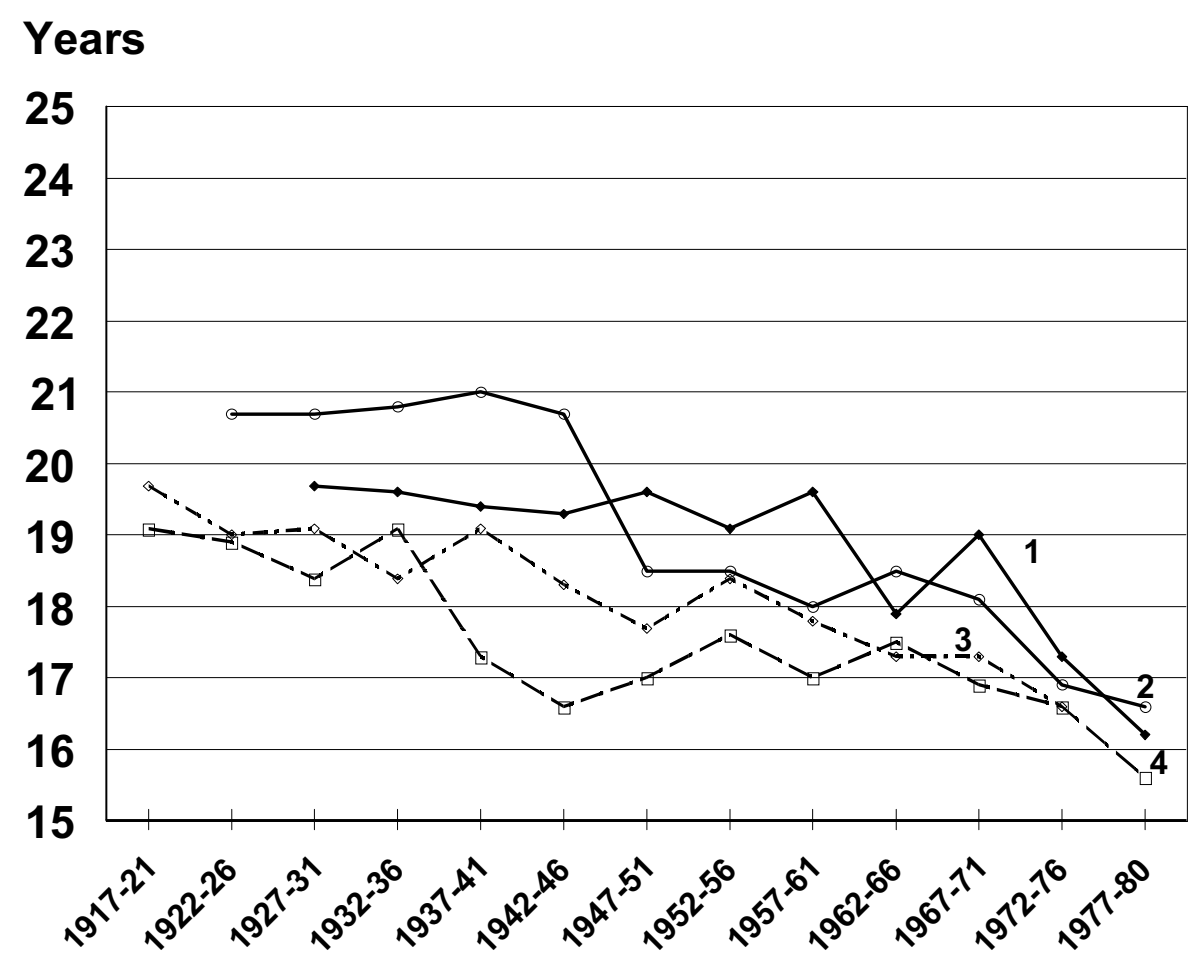

1. St. Petersburg 1996

2. Estonia 2000

3. Finland 1992 $\cdot-0-$.

4. Sweden 1996 $\rightarrow-$

\section{Generations}


According to the NEM surveys, in the first part of the 1990s, teenage sexual initiation has taken place, on the average, half a year earlier than before (Figures 3 and 4). This is true for both genders. Because there are still many (around 10\%) inexperienced men and women in the age group 20-24, the final decrease from the older cohort to the younger one will be actually smaller than that presented here.

Figure 3. Median age at first intercourse. Women by age group.

\section{Years}

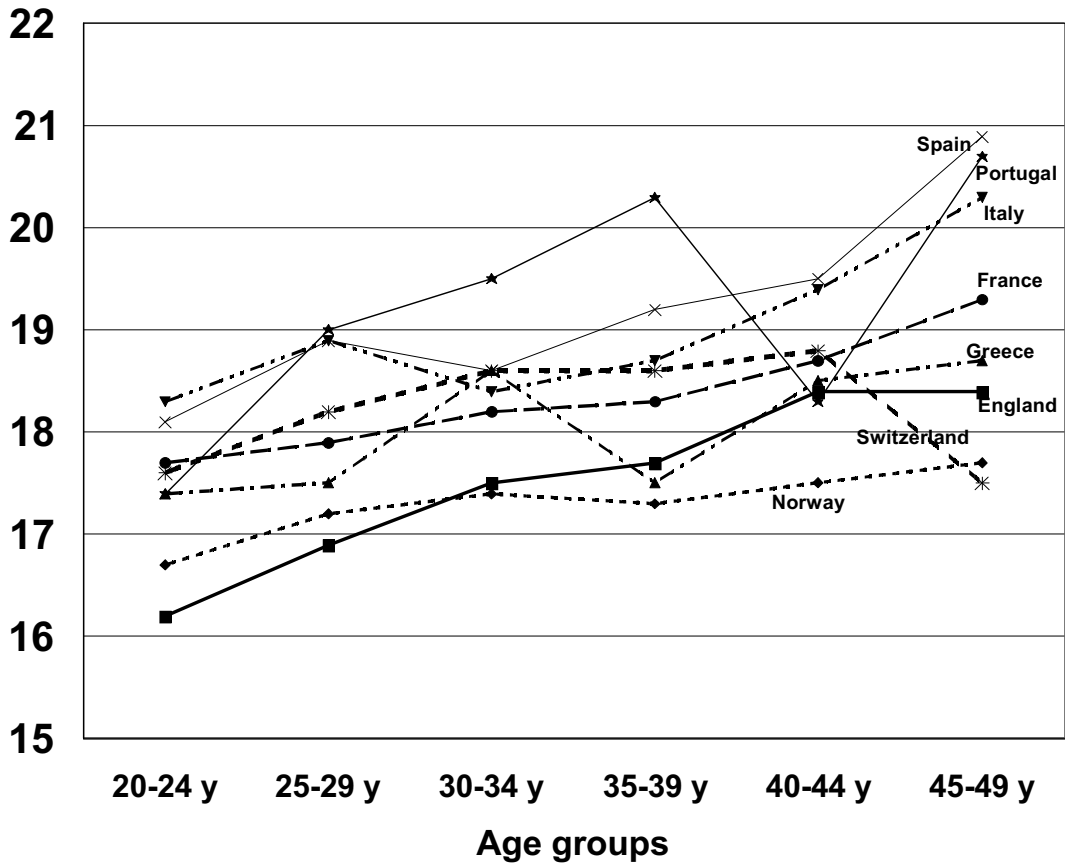

Figure 4. Median age at first intercourse. Men by age group.

\section{Years}

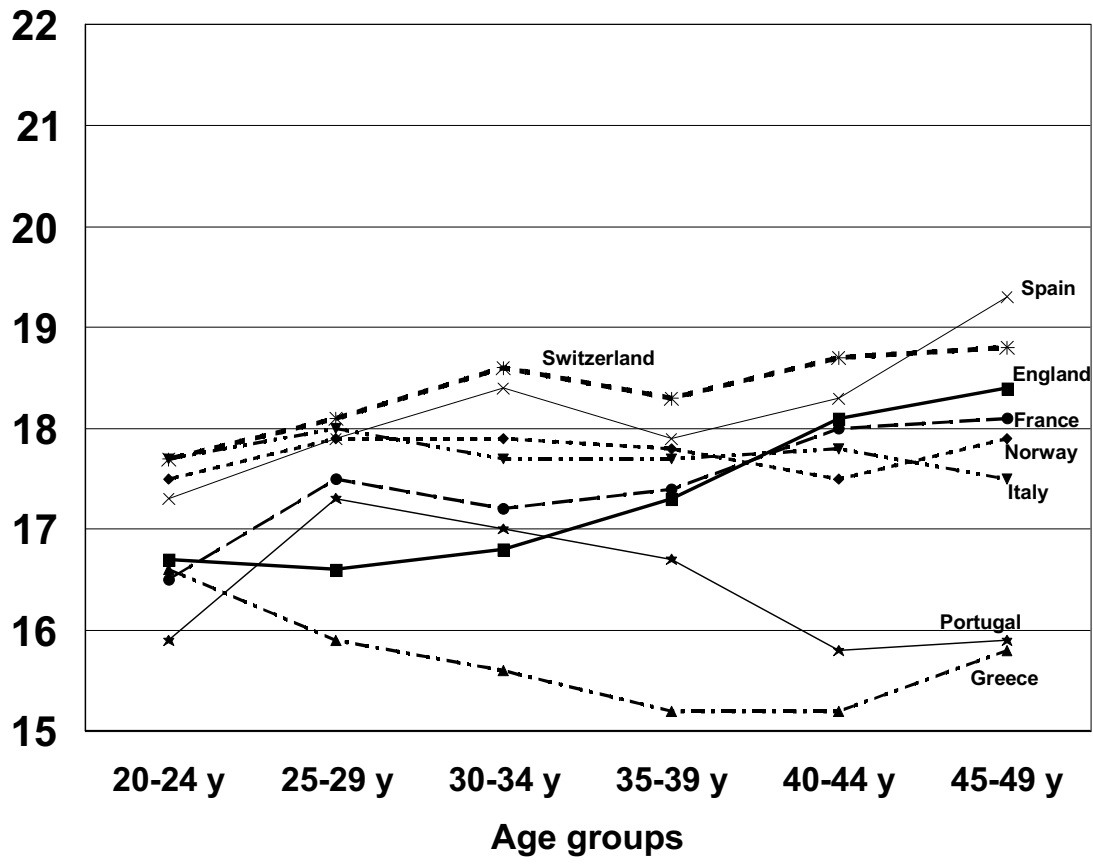

England 1998

France 1998

$\rightarrow-$

Greece 1998

Italy 1998

.......

Norway 1997

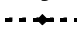

Portugal 1999

Spain 2001

Switzerland 1997

- - -
England 1998

France 1998

Greece 1998

- - -.

Italy 1998

Norway 1997 -- -

Portugal 1999

Spain 2001

Switzerland 1997 
The lowest mean age of sexual initiation in the age group of 20-24 years was 16.2 years for women in England (and 15.9 years for men in Portugal). The highest ages were for women in Italy (18.3 years) and for men in Italy and Switzerland (17.7 years). In all eight countries included in the NEM project the age at first intercourse had declined in the early 1990s among women. In Portugal the decline was greatest. This can be due to the low number of women respondents in this age group in Portugal (only 39). In Greece the mean age at first intercourse was increasing for men; for women it was stable.

Sexual standards in sexual initiation have been different for men and women in many Western European countries (Figure 5). Looking at gender differences in the median age at first intercourse, these standards have been rather equal for young men and women in England, Switzerland and Norway. In Norway girls have been allowed to have their first intercourse at a younger age than has been the case for boys in the same age group. These girls usually go steady with boys who are older than they are. In Italy, Spain, and France boys have had their first experience around a year younger than girls. In Portugal this age difference has been even 2-3 years. In these cases there has been a strong double standard in favor of young men. This double standard has decreased in the youngest generation (in the 1990s) in all other Western European countries, except France.

Figure 5. Gender difference in the median age at first intercourse in NEM surveys by age groups.

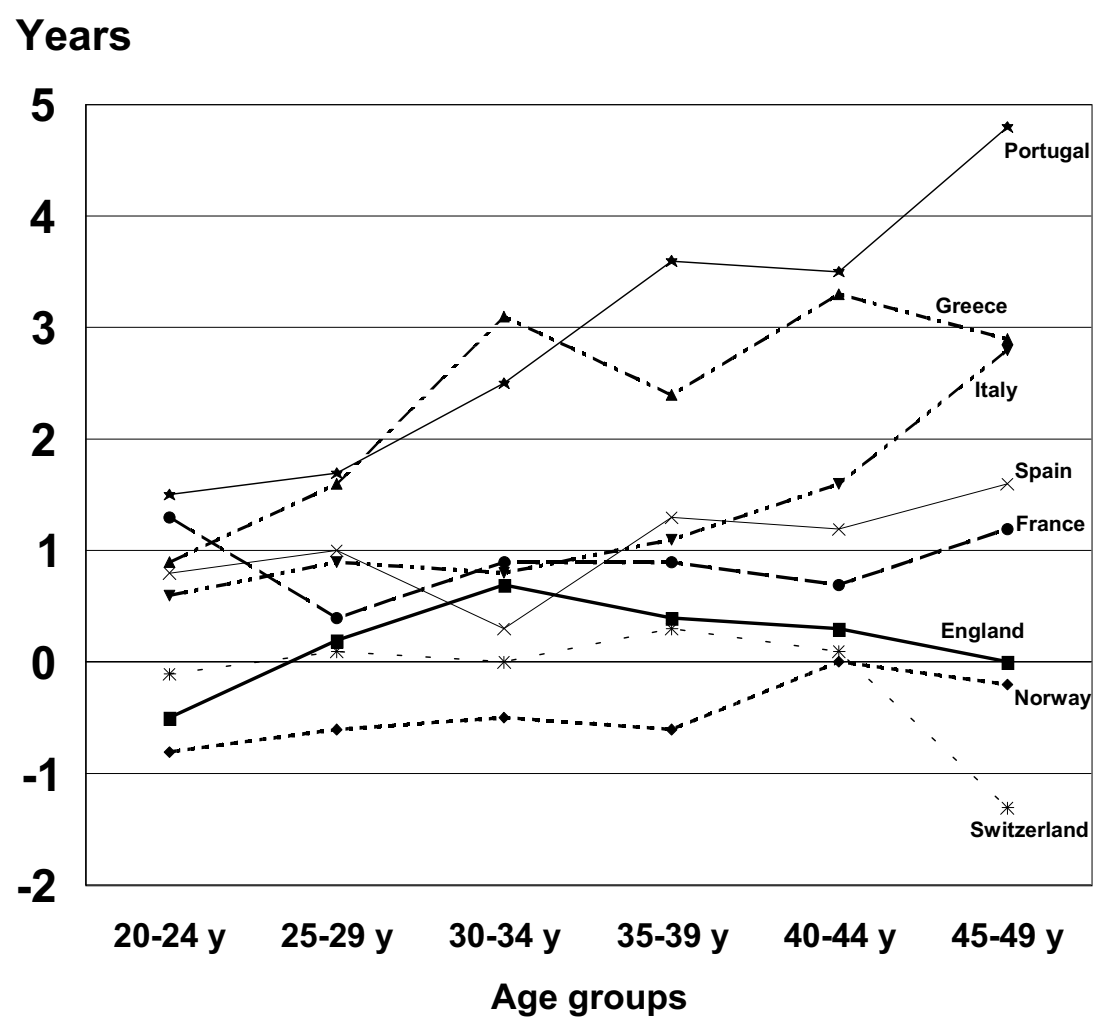

England 1998

France 1998

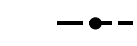

Greece 1998

-- - - -

Italy 1998

-.v-.

Norway 1997

Portugal 1999

$\star \star$

Spain 2001

Switzerland 1997

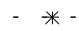


NEM-surveys confirm the earlier findings of the European sex surveys (Bozon \& Kontula, 1998) that before the outbreak of HIV infections in the second half of the 1980s, the average age at first sexual intercourse was rather stable in Western Europe among both genders. Among men the average age at first intercourse was somewhat increasing. In the late 1980s and the early 1990s the average age decreased slightly ( $0.2-0.3$ years) among both genders. The campaigns for preventing HIV infections did not seem to have much impact on teenage sexual initiation. However, one can assume that the decrease of age at first intercourse would have been more pronounced if there had been no AIDS prevention campaigns in the late 1980s.

In the Ukraine CDC survey (1999 Ukraine Reproductive...) the average age at first intercourse has been higher than in Western Europe, but it was decreasing close to the Western figures especially among the youngest cohort, aged 20-24. In the survey conducted in 1999, the female median age at first intercourse was 17.9 years in the cohort aged 20-24, while it was still 20.1 years a generation ago (age group 40-44). In the age group 20-24 half of the women had had their first sexual intercourse before the age of 18 . This was a decrease of two years and it had been accelerating in the cohort that were teenagers after the transition in the 1990s. This development had been rather similar in urban and rural areas of Ukraine.

In the Romania CDC survey (Serbanescu et al., 2001) the median age at first intercourse was close to 20 years for women and around 18 years for men. The median age at first intercourse had been rather stable from one generation to the other. The rate of sexual activity is extremely low among teenagers relative to rates in the West and the double standard is strong. (Women of the World, 2000.) In the survey among the age group 15-19 (Serbanescu \& Young, 1998), only 11\% had had intercourse before they were 16 . In this study group altogether $20 \%$ of women and $41 \%$ of men had had sex. Twenty-five percent of all teenage women - or about half of those who were sexually experienced - had had premarital sex. Men were more than twice as likely as women to have had premarital intercourse. Almost all the young men's first sexual experiences had been premarital.

In the CDC-survey in Moldova in 1997 (Serbanescu et al., 1997), the age at first sexual intercourse was quite high for women. Before the age of 18 only $21 \%$ of the women had experienced intercourse and, before the age of $20,50 \%$ had done so. In the age group 15-24 these proportions were $29 \%$ and $63 \%$, respectively. This shows that there had been some decrease in the average age at first intercourse. The level of sexual experience was similar among various ethnic groups and in urban and rural areas. Young women with low socio-economic status and with less years of schooling were more likely to be sexually experienced at the given age. 
The tendency toward earlier sexual initiation among males compared to females has been observed throughout all the Eastern European countries. Following are examples of teenage sexual experiences by gender: Russian (Saratov) males $54 \%$ and females $32 \%$, Ukrainian males $65 \%$ and females $34 \%$, and Romanian males $45 \%$ and females $25 \%$. Casual sex has also been twice as common among males than females, on the average. One in five of those having sex with casual partners reported paying for sex. (UNICEF, 2000.)

All over Europe, men and women graduates have had their sexual initiation later than early school-leavers (Bozon \& Kontula, 1998, Kontula, 2004). The gap between the proportions of early school-leavers and graduates who had intercourse before 18 was more marked (20 percent difference or more) in Finland, Greece (Athens), Great Britain and among Dutch and German women. The difference was smaller in France, Norway and among Dutch and German men. Portugal was the only country studied where graduates did not behave differently from non-graduates.

Early sexual initiation may be related to a preference for union and raising a family rather than a career. Future graduates have an attitude and a lifestyle in which sexual initiation is not a priority, at least during secondary education. On the other hand, early school-leavers are in a position to make independent decisions and take initiatives much earlier, free from parental control and the constraints of school.

\section{Trends in teenage fertility and pregnancies in Europe}

The average age at which women have their first child has risen two years on the average from 1980 to 1998. The fertility decline in countries of Europe and Northern America has been associated with the rising age at marriage, increasing divorce rates and widespread cohabitation. In Eastern Europe births among unmarried women often result in single motherhood, whereas in Northern Europe they often occur within relatively stable consensual unions that are not legalized.

Before the transition, youth in Central and Eastern Europe tended to marry young and have a first child relatively young. During the transition years, the picture has changed substantially. Youth are less likely to marry, but more likely to have sex at a younger age; teen birth rates have fallen across the region overall, but more of these births are occurring outside marriage and to very young teenage mothers. (UNICEF, 2000.) 
It is estimated that about 14 million women aged 15-19 worldwide gave birth each year in 1995-2000. In 1995-2000 the adolescent fertility rate was 54 births per 1,000 women for the world as a whole. In the more developed regions, the rate was 29 per 1,000, while in the less developed regions the adolescent fertility rate was nearly twice as high, 58 births per 1,000 women. In Eastern Europe, women below the age of 30 contribute more than three-quarters of the total fertility (79 percent), whereas in Western Europe, the corresponding percentage is 56 percent. (World Population..., 2002.) Births to adolescents make up a smaller proportion of births now than in 1980 in most industrialized countries. (Singh \& Darroch, 2000.)

Throughout the 1980s teenage birth rates tended to remain stable or decreased in Western Europe (Figure 6). In some Central European countries birth rates decreased considerably. In the early 1990s teenage fertility rates decreased a lot also in most Western European countries. The United Kingdom and Iceland had the highest rate, around 30 per 1,000. The second category included Austria, Portugal, Greece and Ireland, where the rate was around 20 per 1,000. In other European Union countries the rate was around 10 per 1,000 or even lower (in the Netherlands and Switzerland it was 6-7 per 1,000). The percentage of 20-year-old women who have already given birth ranged from 2 percent (Switzerland) to 13 percent (UK).

Figure 6. Live births per 1,000 women aged 15-19.
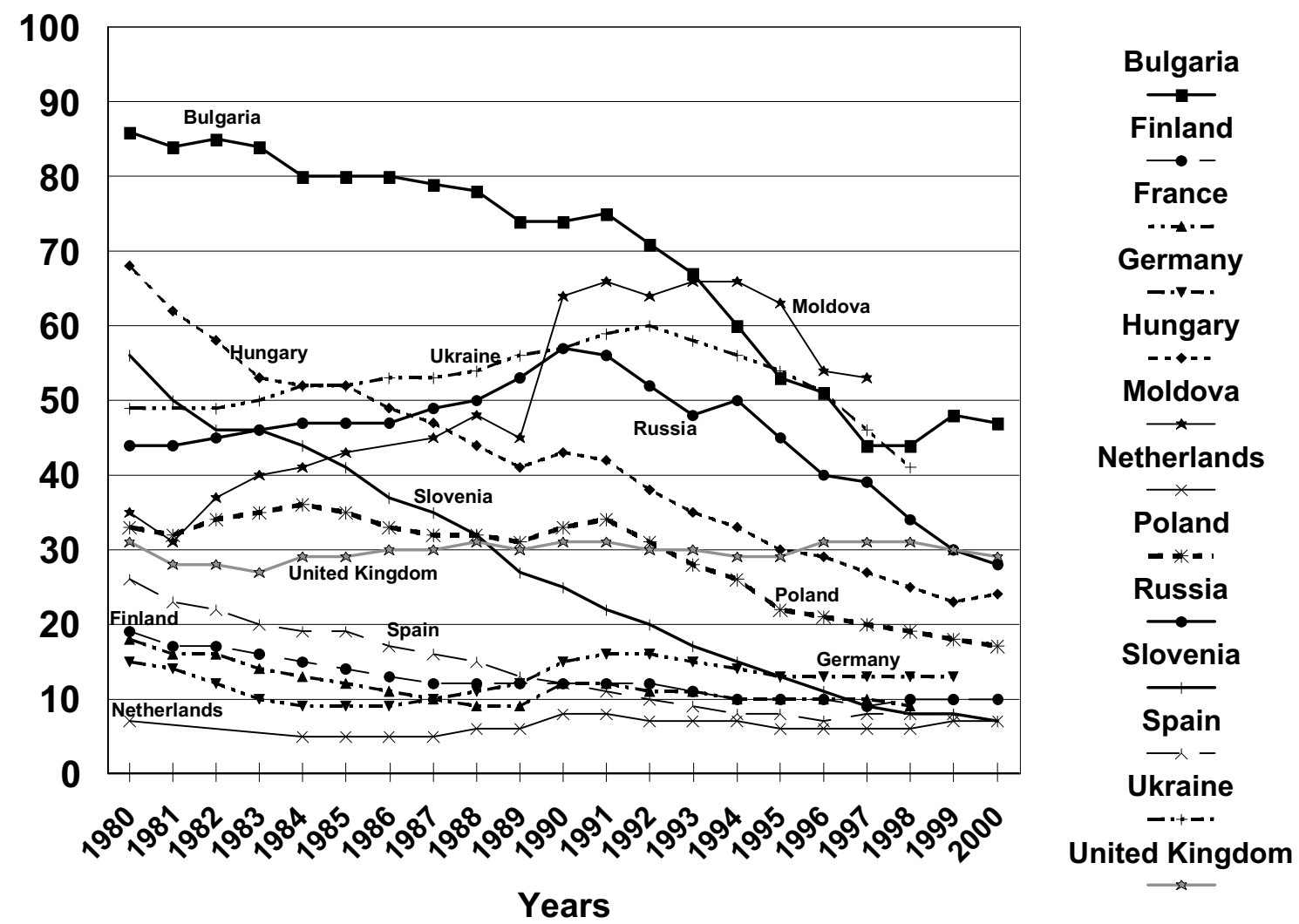
Table 1. Live births per 1,000 females in the age group 15-19 in the European countries in 1990-2000.

\begin{tabular}{|c|c|c|c|c|c|c|c|c|c|c|c|}
\hline Live Births & 1990 & 1991 & 1992 & 1993 & 1994 & 1995 & 1996 & 1997 & 1998 & 1999 & 2000 \\
\hline Albania & 25 & 15 & 16 & 17 & 21 & 23 & 23 & 19 & 17 & 16 & \\
\hline Armenia & 70 & 77 & 83 & 77 & 68 & 56 & 53 & 44 & 43 & 31 & 29 \\
\hline Austria & 20 & 22 & 22 & 21 & 19 & 17 & 16 & 15 & 14 & 13 & 13 \\
\hline Azerbaijan & 26 & 32 & 36 & 39 & 42 & 38 & 37 & 42 & 38 & 33 & 30 \\
\hline Belarus & 44 & 45 & 46 & 43 & 43 & 39 & 36 & 33 & 30 & 30 & 28 \\
\hline Belgium & 11 & 11 & 11 & 10 & 10 & 9 & 10 & 10 & & .. & .. \\
\hline Bosnia and Herzegovina & 38 & & & & & & 31 & 36 & 26 & & \\
\hline Bulgaria & 74 & 75 & 71 & 67 & 60 & 53 & 51 & 44 & 44 & 48 & 47 \\
\hline Croatia & 29 & 25 & 22 & 20 & 19 & 18 & 21 & 20 & 16 & 16 & 16 \\
\hline Cyprus & 34 & 31 & 32 & 24 & 21 & 18 & 16 & 14 & 13 & 13 & 11 \\
\hline Czech Republic & 50 & 51 & 46 & 42 & 32 & 24 & 19 & 17 & 15 & 14 & 13 \\
\hline Denmark & 9 & 9 & 9 & 9 & 9 & 8 & 8 & 8 & 8 & 8 & 8 \\
\hline Estonia & 50 & 48 & 50 & 43 & 39 & 36 & 34 & 30 & 27 & 26 & 26 \\
\hline Finland & 12 & 12 & 12 & 11 & 10 & 10 & 10 & 9 & 10 & 10 & 10 \\
\hline France & 12 & 12 & 11 & 11 & 10 & 10 & 10 & 10 & 9 & 10 & 11 \\
\hline Georgia & 60 & 62 & 53 & 61 & 74 & 72 & 66 & 61 & 58 & 51 & 39 \\
\hline Germany & 15 & 16 & 16 & 15 & 14 & 13 & 13 & 13 & 13 & 13 & . \\
\hline Greece & 20 & 18 & 17 & 15 & 14 & 13 & 12 & 12 & 12 & 11 & $\because$ \\
\hline Hungary & 43 & 42 & 38 & 35 & 33 & 30 & 29 & 27 & 25 & 23 & 24 \\
\hline Iceland & 39 & 35 & 26 & 23 & 23 & 23 & 22 & 24 & 25 & 25 & 22 \\
\hline Ireland & 17 & 18 & 17 & 17 & 16 & 16 & 16 & 18 & 19 & 20 & 19 \\
\hline Italy & 8 & 8 & 7 & 7 & 7 & 6 & 6 & 5 & 6 & 7 & 7 \\
\hline Latvia & 48 & 50 & 49 & 44 & 33 & 30 & 26 & 22 & 19 & 20 & 19 \\
\hline Lithuania & 41 & 46 & 46 & 42 & 41 & 40 & 37 & 32 & 29 & 26 & 24 \\
\hline Luxembourg & 12 & 13 & 12 & 13 & 11 & 10 & 10 & 9 & 9 & 10 & 13 \\
\hline The former Yugoslav & & & & & & & & & & & \\
\hline Republic of Macedonia & 44 & 43 & 42 & 47 & 46 & 44 & 39 & 37 & 34 & 31 & 32 \\
\hline Malta & 11 & 12 & 12 & 13 & 11 & 10 & 17 & 17 & 17 & 17 & 18 \\
\hline Moldova & 64 & 66 & 64 & 66 & 66 & 63 & 54 & 53 & & & \\
\hline Netherlands & 8 & 8 & 7 & 7 & 7 & 6 & 6 & 6 & 6 & 7 & 7 \\
\hline Norway & 17 & 16 & 15 & 14 & 14 & 13 & 13 & 13 & 12 & 12 & 12 \\
\hline Poland & 33 & 34 & 31 & 28 & 26 & 22 & 21 & 20 & 19 & 18 & 17 \\
\hline Portugal & 24 & 24 & 23 & 22 & 21 & 20 & 20 & 21 & 21 & 21 & 22 \\
\hline Romania & 52 & 52 & 50 & 49 & 46 & 42 & 40 & 40 & 39 & 39 & 39 \\
\hline Russian Federation & 57 & 56 & 52 & 48 & 50 & 45 & 40 & 39 & 34 & 30 & 28 \\
\hline Slovak Republic & 49 & 53 & 49 & 46 & 39 & 33 & 30 & 29 & 27 & 25 & 24 \\
\hline Slovenia & 25 & 22 & 20 & 17 & 15 & 13 & 11 & 9 & 8 & 8 & 7 \\
\hline Spain & 12 & 11 & 10 & 9 & 8 & 8 & 7 & 8 & 8 & 8 & 9 \\
\hline Sweden & 14 & 13 & 11 & 11 & 9 & 8 & 8 & 7 & 6 & 7 & 7 \\
\hline Switzerland & 6 & 8 & 7 & 6 & 6 & 6 & 6 & 6 & 6 & 6 & 6 \\
\hline Turkey & 57 & 56 & 55 & 54 & 53 & 52 & 51 & 50 & 49 & 57 & 56 \\
\hline Ukraine & 57 & 59 & 60 & 58 & 56 & 54 & 51 & 46 & 41 & & \\
\hline United Kingdom & 31 & 31 & 30 & 30 & 29 & 29 & 31 & 31 & 31 & 30 & 29 \\
\hline Serbia and Montenegro & 43 & 41 & 37 & 36 & 34 & 33 & 30 & 28 & 26 & 25 & 25 \\
\hline
\end{tabular}

Source: Recent demographic developments in Europe 2001, Council of Europe. 
In the 1990s teenage birth rates have been highest in Eastern Europe, second highest in Central Europe and the lowest in Western Europe. The UK is an exception: it had as high a rate as Russia. In addition, the UK teenage birth rate has not decreased since the early 1980s. On the contrary, Slovenia is a great success story; its teenage birth rate was only one tenth in 2000 compared to 1980 . Hungary and Bulgaria have also been able to halve their rates during this time period. Quite in contrast to this, the Moldovan teenage birth rates were higher in the 1990s than in the 1980s.

In the 1990s the rate of teenage births generally decreased in the EU (the actual rate was between 12 and 25 per 1,000 girls aged 15-19 years). The lowest rates (5-7) are found in Italy, Switzerland, the Netherlands, Sweden and Slovenia, and the second lowest rates (8) in Spain and Denmark (Table 1). The highest rates are to be found in the United Kingdom (30), Iceland (25) and Portugal (21). The second highest rates (13-16) are in Austria, Ireland, Germany, Norway and Greece. The differences in teenage pregnancies, e.g. 30 per 1,000 girls aged 15-19 years in the UK and 5-6 per 1,000 in Italy and Switzerland, are striking.

Teen birth rates are still high in most transitional countries relative to Western countries (Figure 7). The birth rate is currently close to 50 per 1,000 for women aged 1519 in Ukraine, the Republic of Moldova, Georgia, Turkey and Bulgaria. Rates are around 40 per 1,000 for women in Armenia, Azerbaijan, Macedonia and Romania. Rates are close to 30 in Belarus, Estonia, Hungary, Lithuania, the Slovak Republic and the Russian Federation. The highest decreases have taken place in the 1990s in some Central European countries.

Birth rates were higher in 1995 than in 1970 in only eight of the countries where data was available for both years. All of these are in Eastern Europe - Armenia, Belarus, Estonia, Georgia, Lithuania, Macedonia, the Russian Federation and Ukraine. (Singh \& Darroch, 2000.) In 19 of the 28 nations under UNICEF review, births to teenagers have more than halved in 30 years. Giving birth while still a teenager is strongly associated with disadvantage in later life. (UNICEF, 2001b.)

The rate of teenage pregnancies was as high as $60-70$ per 1,000 women still in the early 1990s in many Eastern European countries and in countries of the former Soviet Union. Under socialism, the centrally planned economy could easily be directed towards a restriction of the supply of market contraceptives, while the state imposed restrictions on the implementation of clinical contraceptive methods (sterilization). The reason was also an economic one: the regime could not afford to import modern contraceptive devices. (Philipov \& Dorbritz, 2003.) One of the consequences was the high rate of teenage pregnancies. 
Figure 7. Live births per 1,000 women aged 15-19.

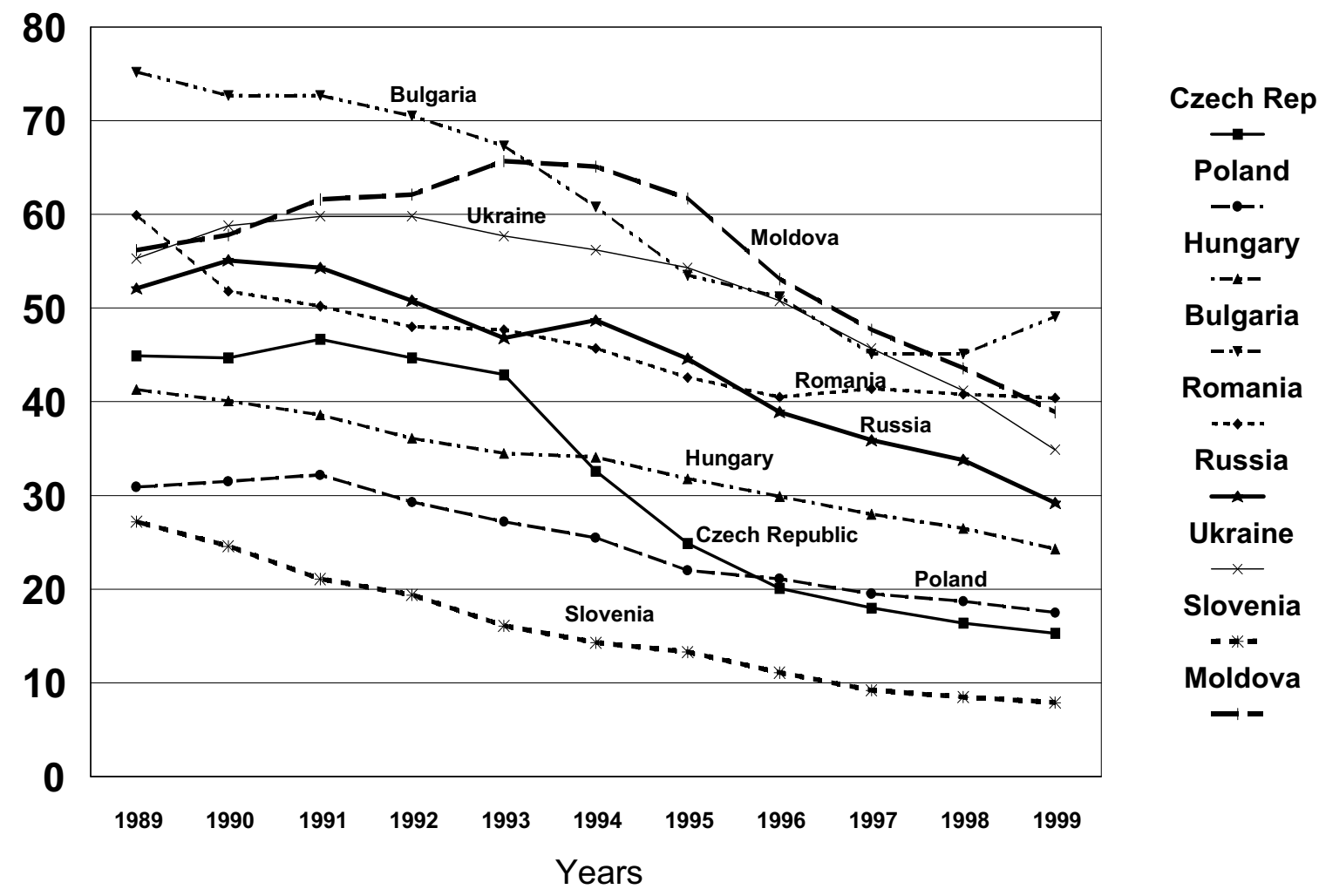

In all developed nations in Europe, excluding Ireland, teenage birth rates were lower in 1998 than in 1970. Other countries with a low decrease (less than 50\%) in teenage birth rates during these 30 years were the UK, the Slovak Republic, Poland and Portugal. The decrease had been at least fourfold in the Netherlands, Switzerland, Italy, Denmark, Sweden, France, Norway, Germany and Austria. Actual teenage birth rates were higher than expected on the basis of each country's total fertility in the Czech Republic, the Slovak Republic, Hungary, Poland, Portugal and the UK. These countries had not actively promoted sexual health among their teenage population.

\section{Conclusions}

National sex surveys conducted in Europe in the late 1980s and in the 1990s show that teenage sexual initiation has been in transition during the last few years. This transition started first in the Nordic countries and then in most other Western European countries. The mean age of women at first intercourse decreased after the 1960s by 2-3 years in all Western European countries. Since the 1980s this age has been rather stable. However, in the first part of the 1990s there has been some decrease in the mean age at first intercourse. A similar transition has started in Eastern Europe one generation (20-30 years) later. There is no evidence that the HIV epidemic and related prevention campaigns had any impact on the age of sexual initiation in Europe. Mean ages at first intercourse are 17-18 years for men and women in Western and Central Europe, and 20 years for women in some Eastern European countries. In 
Southern and Eastern Europe a double sexual standard prevails: it was less acceptable for women to have sexual experiences before marriage than for men.

In most Western Europe countries the age at first sexual intercourse was almost completely unrelated to marriage. In Eastern European countries they were much more interlinked. Women were older at sexual initiation, they married younger and they gave birth to their first child five years younger than in the West. Teenage birth rates were 3-4 times higher in Eastern Europe than in the West. The highest rates in Europe were 50 per 1,000 and the lowest 5-6 per 1,000 in the late 1990s. In most countries birth rates had decreased in the 1990s, but there were also countries where these rates had been rather stable at a high level. High rates were due to missing and unreliable contraceptive devices.

The decrease in teenage birth rates is partly explained by the general delaying trend in childbearing and at the age at first birth. This has been found both in Western and Eastern Europe. In most European countries the mean age at first birth has increased 1-2 years from 1990 to 2002. The mean age of women at first marriage has increased as much or even more in Europe. On the other hand, these means are still much lower in Eastern Europe and childbearing and marriage are there more closely linked to each other. Teenagers all over Europe are now sexually more active than before but thanks to contraceptives, they get pregnant and marry at an older age than what previously was the pattern.

The pragmatic European approach to teenage sexual activity, expressed in the form of widespread provision of confidential and accessible contraceptive services to adolescents is seen as a central factor in explaining the more rapid declines in teenage childbearing in Northern and Western European countries. (Singh \& Darroch, 2000.) Shifts in value orientation resulting from greater individual autonomy in all domains are consistent with a lifestyle in which people make their own choices about marriage and cohabitation, where they are free to have children within or outside marriage, to raise them alone or with a partner, and can have them early or late in life or not at all.

Factors that play an important role in explaining recent trends include the greater importance ascribed to educational achievement, the increased motivation among young people to delay pregnancy and childbearing in order to achieve higher education levels and to gain job skills before forming a family, as well as the improvements in knowledge of and access to the means of preventing unplanned pregnancy. (Singh \& Darroch, 2000.) There is lower motivation to avoid pregnancy among teenagers who have lower educational and job aspirations and expectations, among those who are not doing as well in school and among those in poor and single-parent families. 
The trend toward smaller families is related to the utilitarian significance of childbearing: its practical advantages and disadvantages. People will seek selfexpression and will focus on their own well-being and on actions they perceive as giving meaning to their lives (Van de Kaa, 2001). In Russia the decrease in adolescent fertility was caused by the rising social aspirations of young adults. This was observed in a series of surveys carried out in Moscow and its provinces (Magun, 1998). The "new home economics" approach (Becker, 1994) argues that the rising costs of children bring about a decrease in natality, and that is what was observed.

Many of the countries of Central and Eastern Europe and the Baltic States have experienced rapid declines in adolescent fertility during the 1990s. Family planning organizations grew and developed large-scale activities for spreading knowledge about modern contraceptive methods. Towards the end of the 1980s and during the 1990s the usage of modern contraceptive methods increased considerably. The right of parents to have the number of children they desire was legally formulated. Higher education raised women's human capital and hence their earnings. The opportunity costs of time spent on the family and on rearing children increased. Thus births decreased. (Philipov \& Dorbritz, 2003.)

In Western Europe decreasing trends in teenage pregnancies and STIs were due to the secularization of sex and the liberalization of attitudes. They made possible the distribution of relevant information on sexual issues, sex education and related public health services. HIV prevention campaigns in the 1980s were very important in providing the young generation with the knowledge and skills that they needed in order to protect themselves from health hazards. Unfortunately similar knowledge was not available in Eastern Europe. After the transition in Eastern Europe in the early 1990s, the new generation was freer to make personal choices but usually without the knowledge and the means of protecting themselves. At the same time public health resources were cut back. One of the consequences were the increasing trends in teenage STIs in the East (Kontula, 2003). Teenage pregnancies also remained at a high level.

Kovács (1999) has listed concerns in reproductive health issues in the Eastern European region. These include the lack of common definitions and adequate statistical data, the lack of training of professionals, deficiencies in knowledge about current family planning methods among professionals, consumers, policy makers and media representatives, the lack of the modern contraceptive supplies needed to meet the needs of the populations of the participating countries, the lack of sex education in schools, elevated maternal mortality, the high level of induced abortions, the high prevalence of infertility and the lack of ability to prevent, diagnose and 
treat sexually transmitted diseases. In the following most of these points will be dealt with in more detail.

\section{Policy implications}

Work for improvement of sexual and reproductive health and rights can be successful only in a society that is open and socially tolerant on sexual issues. There is a great deal of evidence from research that 'cultural openness', where sex is discussed in an open and accepting manner rather than being ambivalent, or the way in which young people's sexuality and sexual behavior is socially represented and communicated, has a considerable impact on the effectiveness of local and national interventions. (Kontula, 2004.)

In a society without openness in sexual issues, the government is less motivated to provide resources for sexual health services, the personnel in charge for those services are less motivated to improve their expertise in sexology, teachers are less willing to provide sex education to their students (and also to educate themselves), teenagers are less willing to raise questions concerning sexual issues, partners will communicate less, for example, about precautions and their preferences in their sexual interactions etc. Openness in the public discussion of sexual issues will be of crucial help in sexual and reproductive health promotion at all societal levels. For instance, it can promote a more positive attitude towards condom use and an increased familiarity with condoms. It can also balance and correct information that has maintained mistrust and misinformation about modern contraceptive methods.

Each country needs an action plan on how to promote reproductive health. This plan can be in the form of a strategy or program, including both resources allocated to sexual health services as well as an action plan for distributing and advertising information that will help to prevent unwanted pregnancies and other sexual health hazards. This is wise policy also from the viewpoint of a state budget. In the UK the Faculty of Family Planning and Reproductive Health has calculated in 1999 that an average investment of $£ 80$ per year to provide contraception to a teenager under 18 will result in a direct saving to the health budget of $£ 750$ on abortion or maternity costs for each pregnancy prevented.

Countries should ensure the provision of unbiased, scientific and clearly understandable information and counseling on sexual and reproductive health, including the prevention of unwanted pregnancies and the risks involved in unsafe abortions carried out under unsuitable conditions. Advice and counseling must be confidential and non-judgmental. (Van Lancker, 2002.) Counseling will be needed also for preventing and treating sexual abuse as well as for gaining control of one's own sexuality. Young people often also need help to enable acceptance and enjoyment of the full potential of their sexuality. 
The aim of youth development programs is to tackle the education and life options of young people, their school performance, belief in the future and general risktaking behavior. These programs can, for example, equip young women, in particular, with the communication skills to negotiate sexual intercourse and contraception, and with motivation to delay early intercourse and childbearing. At the family and community level, they address 'nonsexual risk factors' - poverty, social disorganization and isolation. They have been effective in reducing actual rates of teenage pregnancy and childbearing.

The provision of sexuality education in the schools, which has increased in many countries (as part of societal efforts to counter the epidemic of HIV and AIDS), is likely to have made a cumulative contribution to improved knowledge of contraception, ability to negotiate contraceptive use and the effectiveness of contraceptive use among adolescents. (Singh \& Darroch, 2000.) The provision of sex education should be linked to access to contraceptive services. For example, health service staff (school nurses) could lead sex education sessions given in schools to provide a 'bridge' into services. School nurses can be very effective in promoting sexual health.

In some Western countries adolescents have quite good knowledge without sex education in schools, thanks to the media and other information sources that are easily available. In other countries these sources are missing and adolescents need very comprehensive education from school. And this knowledge is not enough. Sex education needs to provide adolescents also with motivation to behave responsibly and skills in how to succeed in preventing the risks. In order to be successful, this message needs to be delivered to the whole population via media advertising campaigns and with the help of communication via the Internet, leaflets, billboards etc. Together with proper resources (including provision of contraceptives, and knowledge where, when and from whom to acquire them) sexual and reproductive health can be successfully promoted.

There is overwhelming evidence showing that young people are especially sensitive to the way in which they are addressed, particularly by authority figures. They strongly reject communication they perceive as patronizing, authoritarian or not addressed to them as equals. This includes sources that they perceive as treating them as children, that try to be like them or that tell them what to do or to believe. The sources they respect treat them as equals, take the trouble to find out what their needs are and empathize with them, and then provide the necessary information to help them decide for themselves. (Teenage Pregnancy..., 2000.) 
Responding to the needs of young people is not the responsibility of government alone; communities, parents, churches and civil society need to join in efforts to reach young people. NGOs, including women's advocacy groups, have an important role to play in advocating with the government and with the public, and in shaping the implementation of youth sexual and reproductive health policies. (Greene et al, 2002.) Sexual education should be a collaborative effort among school personnel, community youth workers, reproductive health clinicians, parents and communities.

Social exclusion, poverty, low educational attainment and access are also key factors in this complex public health issue. Governments should provide contraceptives and sexual and reproductive health services free of charge, or at low cost, for underserved groups, such as young people, ethnic minorities and the socially excluded. People living in poverty should get better access to reproductive and sexual health services, and they should be offered the choice of contraception and the prevention/diagnosis of sexually transmittable diseases. Emergency contraception should be promoted as standard practice within sexual and reproductive health care. Walkin clinics outside school hours in accessible locations might improve the uptake of services and the effective use of contraceptives.

\section{References}

Becker, Gary S. 1994. A Treatise on the Family: Enlarged Edition. Cambridge, Massachusetts: Harvard University Press.

Bozon, Michel and Osmo Kontula. 1998. Sexual initiation and gender: A cross-cultural analysis of trends in the 20th century. In: Sexual Behaviour and HIV/AIDS in Europe: Comparisons of National Surveys, edited by Michel Hubert, Nathalie Bajos, and Theo Sandfort, pp. 37-67. London: UCL Press.

Greene, Margaret E., Zohra Rasekh, Kali-Ahset Amen, Nada Chaya, and Jenifer Dye. 2002. In: This Generation: Sexual \& Reproductive Health Policies for a Youthful World. Washington: Population Action International.

Haavio-Mannila, Elina, and Osmo Kontula. 2001. Seksin trendit: Meillä ja naapureissa [Trends in Sex Life: At home and in the neighboring countries]. Helsinki: WSOY.

Haavio-Mannila, Elina and Osmo Kontula. Sexual Trends in the Baltic Sea Area. Publications of the Population Research Institute, Series D41. Helsinki: The Population Research Institute, Family Federation of Finland 2003.

Kontula, Osmo and Elina Haavio-Mannila. 1995. Sexual Pleasures: Enhancement of Sex Life in Finland, 1971-1992. Hampshire: Dartmouth.

Kontula, Osmo 2000: Cultural Variations of Sexual Initiation. In: Sexuality in the New Millennium, edited by EML. Ng, J.J. Borrás-Valls, M. Pérez-Conchillo and E. Coleman. Proceeding of the 14th World Congress of Sexology, Hong Kong SAR, pp. 107-110. Bologna: Editrice Compositori.

Kontula, Osmo 2003. Trends in Teenage Sexual Behaviour, Pregnancies, Sexually Transmitted Infections and HIV infections in Europe. In: Reproductive health behaviour of young Europeans Volume 1, pp. 77-137. Population Studies No. 42. Strasbourg: Council of Europe Publishing. 
Kontula, Osmo 2004. Reproductive health in Europe: the role of education and information. In: Reproductive health behaviour of young Europeans Volume 2. Population Studies No. x. Strasbourg: Council of Europe Publishing (in press).

Kovács, L. 1999. From abortion to contraception in Europe. European Journal of Contraception \& Reproductive Health Care 4:(4):229-36.

Lewin, B., K. Fugl-Meyer, G. Helmius, A. Lalos, and S-A. Månsson. 1998. Sex i Sverige: Om sexuallivet i Sverige 1996 [Sex in Sweden: About sexual life in Sweden 1996]. Stockholm: Folkhälsoinstitutet 11.

Philipov, Dimiter and Jürgen Dorbritz. 2003. Demographic consequences of economic transition in countries of central and eastern Europe. Strasbourg: Council of Europe Publishing. Population studies No. 39.

Serbanescu, Florina, Leo Morris, Mihai Stratila, and Octavian Bivol. 1997. Reproductive health survey Moldova, 1997: Final report. Atlanta. GA: Centers for Disease Control and Prevention.

Serbanescu, Florina and Morris L. Young. 1998. Young Adult Reproductive Health Survey, Romania 1996, Final Report. Atlanta, GA: Centers for Disease Control and Prevention.

Serbanescu, Florina, Leo Morris, and Mona Marin. 2001. Reproductive health survey Romania, 1999: Final report. Atlanta, GA: Centers for Disease Control and Prevention.

Singh, Susheela and Jacqualine E Darroch. 2000. Adolescent Pregnancy and Childbearing: Levels and Trends in Developed Countries. Family Planning Perspectives 32:(1):14-23.

Teenage Pregnancy in England: desk research to inform the national campaign, April 2000. London: Teenage Pregnancy Unit.

UNICEF 2000. Young People in Changing Societies. Regional Monitoring Reports, No. 7. Florence: UNICEF Innocenti Research Centre.

UNICEF 2001b. A Decade of Transition. The Monee Project. CEE/CIS/Baltics. Regional monitoring report No. 8. Florence: UNICEF Innocenti Research Centre.

United Nations Development Programme 1996. Human Development Report. New York: Oxford University Press.

Van de Kaa, Dirk J. 2001. Postmodern Fertility Preferences: From Changing Value Orientation to New Behavior. In: Global Fertility Transition, edited by Rodolfo A. Bulatao and John B. Casterline. Population and Development Review, pp. 290-331. A Supplement to Volume 27. New York: Population Council.

Van Lancker, Anne E.M. 2002. European Parliament Report on Sexual and Reproductive Health and Rights (2001/2128 (INI)). Committee on Women's Rights and Equal Opportunities.

Women of the World 2000. Laws and policies affecting their reproductive lives. East Central Europe. Edited by the Centre for Reproductive Law and Policy. New York.

World Population Monitoring 2002. Reproductive rights and reproductive health: selected aspects. Commission on Population and Development. New York: United Nations.

1999 Ukraine Reproductive Health Survey. Final Report. Kiev International Institute of Sociology. Centers for Disease Control and Prevention. United States Agency for International Development.

1999 Russia Women's Reproductive Health Survey: Follow-up Study of Three Sites. Preliminary Report. Russian Centre for Public Opinion and Market Research. Centers for Disease Control and Prevention. United States Agency for International Development. March 2000. 